\title{
Effects of Mollugo pentaphylla extract on monosodium urate crystal-induced gouty arthritis in mice
}

\author{
Yun Mi Lee, Eun-Jung Shon, Ohn Soon Kim and Dong-Seon Kim (1)
}

\begin{abstract}
Background: Gout is an inflammatory condition induced by the deposition of monosodium urate (MSU) crystals in joints and soft tissues, and it can lead to acute or chronic arthritis. MSU are pro-inflammatory stimuli that can initiate, amplify and sustain an intense inflammatory response. In this study, we evaluated the anti-inflammatory effect of an extract of Mollugo pentaphylla (MPE) on MSU-induced gouty arthritis in a mouse model.

Method: An MSU crystal suspension (4 mg/50 $\mu \mathrm{L}$ ) was injected intradermally into the right paw. The mice were orally administered MPE (150 mg/kg or $300 \mathrm{mg} / \mathrm{kg})$ or the positive control drug colchicine $(1 \mathrm{mg} / \mathrm{kg}) 1 \mathrm{~h}$ before the MSU crystals were injected and then once daily for 3 days. The effects of MPE included inflammatory paw edema and pain upon weight-bearing activity, and we evaluated the inflammatory cytokine expression and paw tissue inflammation-related gene expression.
\end{abstract}

Results: MPE suppressed inflammatory paw edema and pain in the MSU-induced mice. MPE showed antiinflammatory activity by inhibiting the production of TNF-a, interleukin (IL)-1 $\beta$, NLRP3 inflammasome and NF-KB.

Conclusion: These results suggest that MPE has potent anti-inflammatory activities and may be useful as a therapeutic agent against gouty arthritis.

Keywords: Gouty arthritis, Monosodium urate crystal, Mollugo pentaphylla, Cytokines, Inflammasome, NF-kB

\section{Background}

Gout is characterized by increased blood uric acid levels (hyperuricemia) and the deposition of monosodium urate (MSU) crystals within intra-and/or peri-articular areas, which leads to excruciating pain and inflammatory processes [1]. Under long-standing hyperuricemia, MSU crystal deposits further induce chronic inflammatory responses that may lead to joint structure damage, socalled gouty arthritis or chronic gout, which is usually associated with the presence of subcutaneous MSU crystal deposits or tophi [2]. MSU crystals can cause acute, self-limited, inflammatory flares, which are likely triggered by crystal shedding from the cartilage surface into the joint space, where they can interact with resident cells. During attacks of gouty arthritis, MSU crystals

\footnotetext{
* Correspondence: dskim@kiom.re.kr

Korean Medicine Convergence Research Division, Korea Institute of Oriental Medicine (KIOM), 1672 Yuseong-daero, Yuseong-gu, Daejeon 34054, South
} Korea

(c) The Author(s). 2017 Open Access This article is distributed under the terms of the Creative Commons Attribution 4.0 International License (http://creativecommons.org/licenses/by/4.0/, which permits unrestricted use, distribution, and reproduction in any medium, provided you give appropriate credit to the original author(s) and the source, provide a link to the Creative Commons license, and indicate if changes were made. The Creative Commons Public Domain Dedication waiver (http://creativecommons.org/publicdomain/zero/1.0/) applies to the data made available in this article, unless otherwise stated. and are phagocytosed by monocytes/macrophages, resulting in membranolysis and inflammasome activation, which releases interleukin (IL)-1 $\beta$ [3].

The main goals of gouty arthritis therapy are to control pain, reduce inflammatory responses to MSU crystals, and relieve symptoms quickly and safely [4]. Commonly prescribed arthritis medications include nonsteroidal antiinflammatory drugs (NSAIDs), analgesic drugs, corticosteroids and colchicine $[5,6]$. Colchicine is frequently used in the treatment of gout attacks and has specific clinical efficacy and inhibits neutrophil recruitment and activation $[7,8]$. Pre-treatment with intravenous colchicine before intra-articular MSU crystal injections greatly reduces inflammation, suggesting that colchicine targets the initial phase of inflammation $[9,10]$. However, these agents may have serious side effects, such as gastrointestinal toxicity, renal toxicity, or gastrointestinal bleeding. Natural alternative anti-inflammatory supplements have been used to 
mediate the inflammatory process and often produce fewer side effects [11]. Therefore, we focused our research on the discovery of a drug with anti-inflammatory activity from natural resources. In our prior research to find novel arthritis drug, we have screened in animal models over 100 plant extracts which are reported on antiinflammatory effects but not on gouty arthritis.

Mollugo pentaphylla (MP) is an annual herb found in the tropical regions of India, Malaysia, China, Japan and Fiji. The aerial parts of this herb are generally consumed for their central nervous system stimulatory as well as their stomachic, aperients, antiseptic, antiperiodic properties, anticancer, antitoxic diuretic, hepatitis and contusion effects. This plant reportedly contains carotenes, vitamin $\mathrm{C}$, and the triterpenoid saponin mollugogenolA, which exhibits significant antifungal activity [12-15]. In previous reports, Kim et al. showed that MP reduced the Propionibacterium acnes-induced secretion of proinflammatory cytokine IL- 8 in THP-1 cells, which indicated that MP has anti-inflammatory effects [14]. Lin et al. reported that MP water extracts possess antiinflammatory activity and can inhibit carrageenaninduced paw edema [16]. Sahu et al. showed that ethanolic extracts of MP significantly reduced the paw edema induced by carrageenan and cotton-pellet induced granuloma models, which are associated with the anti-inflammatory effects in acute and sub-chronic inflammation models. In addition, MP extracts has analgesic activity by tail immersion and acetic acid induced writhing models [17]. Although MP have been showed anti-anflammatory effects and edema suppression effects in animal models, the effects of extract of Mollugo pentaphylla (MPE) on MSU crystal-induced gouty arthritis has not been reported. The MSU crystal-induced animal model is widely used to study measurement inflammatory edema related to soft-tissue inflammation and weight-bearing test to estimate pain in gouty arthritis [18]. Considering the protective effect of MP on the anti-inflammatory activity, the study was designed to investigate the anti-inflammatory effect of MPE in MSU crystal-induced gouty arthritis in a mouse model.

\section{Methods}

\section{MPE preparation}

Whole MP plants were collected in Yangpyung, Kyounggi-do. The plant materials were confirmed taxonomically by Dr. Geung-Joo Lee of the Chungnam National University. A voucher specimen (no. KIOM201701018962) was deposited at the Korean herbarium of Standard Herbal Resources at the KIOM. A dried whole MP plant $(1 \mathrm{~kg})$ was extracted twice with $70 \%$ ethanol (with a $3 \mathrm{~h}$ reflux), and the extract was then concentrated under reduced pressure. The decoction was filtered, lyophilized, and stored at $4{ }^{\circ} \mathrm{C}$ [19]. The yield of the dried extract from crude starting materials was $13.9 \%(w / w)$.

\section{MSU crystal synthesis}

$4 \mathrm{~g}$ of uric acid was dissolved and heated in $800 \mathrm{ml}$ of $\mathrm{H}_{2} \mathrm{O}$ with $\mathrm{NaOH}(9 \mathrm{ml} / 0.5 \mathrm{M})$ and adjusted to $\mathrm{pH} 8.9$ at $60{ }^{\circ} \mathrm{C}$. The solution was cooled overnight in a cold room. The crystals were harvested by decanting the supernatant and then washed and dried. The needle shape and size of the crystals were checked by polarizing light microscopy. The MSU crystals were suspended in $2.5 \%$ Tween 80 in PBS (80 mg/ml) [20].

\section{Induction of gouty arthritis with MSU crystals in mice}

C57BL6 male mice (7 weeks old, 20-22 g body weight) were purchased from Orient Bio, Seongnam, Korea), The mice were housed in a controlled temperature room at $22 \pm 2{ }^{\circ} \mathrm{C}$, in $55 \pm 10 \%$ relative humidity with a $12 \mathrm{~h}$ : $12 \mathrm{~h}$ light-dark cycle, and they were freely fed commercial standard chow (Dae-Han Bio Link) and were provided tap water ad libitum for 6 days. After acclimation, the mice were housed separately in cages and were familiarized with the testing procedures. C57BL6 male mice ( 8 weeks old, 20-22 g body weight) were divided into the following five groups, which consisted of five animals each: (1) control group, (2) MSU crystal group with MSU injection, $(3,4)$ the MPE-treated group (150, $300 \mathrm{mg} / \mathrm{kg}$ body weight, respectively) with MSU crystal injection and (5) the colchicine (Col) treated group ( $1 \mathrm{mg} / \mathrm{kg}$ body weight) with MSU crystal injection. The MSU crystal suspension $(4 \mathrm{mg} / 50 \mu \mathrm{L})$ was injected intradermally into the right paw. The mice were administered MPE or the positive control drug (colchicine) $1 \mathrm{~h}$ before the MSU crystal injection and then once daily for 3 days. After the treatment with MPE, no evidence of systemic adverse effects was observed in any study group. Four days after MSU crystal injection, the mice were anesthetized using Pentobarbital sodium (Entobal, Hanlim Pharma, Co., Ltd., Korea) and sacrificed. The right paw tissue was removed and homogenized at $4{ }^{\circ} \mathrm{C}$ in RIPA buffer. The homogenate was centrifuged at $14000 \mathrm{rpm}$ for $15 \mathrm{~min}$ at $4{ }^{\circ} \mathrm{C}$, and the supernatant was stored at $-70{ }^{\circ} \mathrm{C}$ until further analysis. All experiments that used animals were approved by the Institutional Animal Care and Use Committee of the Korea Institute of Oriental Medicine (Daejeon, Korea) and was conducted in accordance with the Guide for the Care and Use of Laboratory Animals published by the US National Institutes of Health (Bethesda, MD, United States).

\section{Assessment of inflammatory paw edema}

Inflammatory paw edema was quantified by measuring the thickness of the paw with a Vernier scale at the end of the experimental period. 


\section{Assessment of inflammatory pain}

After arthritis induction, the original weight-bearing capability balance of the hind paws was disrupted. A significant shift of weight from the arthritic site to the contralateral limb, i.e., a weight-bearing deficit, is considered a pain measure and has been shown in joint arthritis models induced by intra-articular MSU crystals [21]. The inflammatory pain was quantified by measuring the weight-bearing capacity of a paw load using a dynamic weight bearing (DWB) device (Bioseb, Boulogne, France) $[22,23]$. The weight distribution ratio was calculated by the following equation: [weight on right hind limb / (weight on right hind limb + weight on left hind limb) $] \times 100$.

\section{Measurement of inflammatory cytokines}

The levels of IL-1 $\beta$ and TNF- $\alpha$ were measured using ELISA kits from R\&D Systems (Minneapolis, MN, USA) according to the manufacturer's protocol.

\section{Real-time PCR analysis}

Total RNA was isolated using TRIzol (Invitrogen, CA, USA), and $0.5 \mu \mathrm{g}$ of total RNA was reverse transcribed into cDNA with the PrimeScript First Strand cDNA Synthesis kit (Bio-Rad, CA, USA). Real-time quantitative PCR was performed with specific primers using a CFX Connect $^{\mathrm{Ts}}$ Real-Time PCR Detection System (Bio-Rad, CA, USA). The primer sequences are shown in Table 1. All real-time PCR experiments were run in quadruple. The mRNA levels of GAPDH were determined for the normalization of the NLRP3, ASC, NF- $\mathrm{kB}$, caspase-1, IL$1 \beta$ and TNF- $\alpha$ mRNA expression values using the CFX Manager $^{\text {TM }}$ Software (Bio-Rad, CA, USA).

Table 1 Real-time PCR primer sequences

\begin{tabular}{|c|c|c|}
\hline Gene & & Primer sequence \\
\hline \multirow[t]{2}{*}{$\mathbb{I L}-1 \beta$} & Forward & 5'-TCTATACCTGTCCTGTGTAATGAAAG-3' \\
\hline & Reverse & 5'-GGCTTGTGCTCTGCTTGTGAG-3' \\
\hline \multirow[t]{2}{*}{ TNF-a } & Forward & 5'-GTGGAACTGGCAGAAGAG-3' \\
\hline & Reverse & 5'-CCATAGAACTGATGAGAGG-3' \\
\hline \multirow[t]{2}{*}{ NF-kB } & Forward & 5'-CTCACCGGCCTCATCCACAT-3' \\
\hline & Reverse & 5'-TGGCTAATGGCTTGCTCCAG-3' \\
\hline \multirow[t]{2}{*}{ NALP3 } & Forward & 5'-TGCTCTTCACTGCTATCAAGCCCT-3' \\
\hline & Reverse & 5'-ACAAGCCTTTGCTCCAGACCCTAT-3' \\
\hline \multirow[t]{2}{*}{ ASC } & Forward & 5'-CAGAGTACAGCCAGAACAGGACAC-3' \\
\hline & Reverse & 5'-GTGGTCTCTGCACGAACTGCCTG-3' \\
\hline \multirow[t]{2}{*}{ Caspase-1 } & Forward & 5'-TCCGCGGTTGAATCCTITTCAGA-3' \\
\hline & Reverse & 5'-ACCACAATTGCTGTGTGTGCGCA-3' \\
\hline \multirow[t]{2}{*}{ GAPDH } & Forward & 5'-AGAAGGTGGTGAAGCAGGCATC-3' \\
\hline & Reverse & 5'-CGAAGGTGGAAGAGTGGGAGTTG-3' \\
\hline
\end{tabular}

\section{Statistical analysis}

The results were expressed as the mean \pm standard error of the mean (SEM) and analyzed using a one-way analysis of variance (ANOVA) followed by Dunnett's tests for multiple comparisons or unpaired Student's $t$-tests for two-group comparisons. All analyses were performed using Prism 7.0 (GraphPad Software, San Diego, CA, USA), and $P$-values $<0.05$ were considered statistically significant.

\section{Results}

\section{Effect of MPE on MSU crystal-induced paw edema}

To assess the extent of edema, the thickness of the paws of the control and treated mice was measured. As shown in Fig. 1a and b, the MSU crystals in the treatment mice led to a significant increase in the foot thickness compared with that of the control mice; however, the increase in foot thickness was found to be reduced in the MSU crystal-induced mice treated with MPE $(300 \mathrm{mg} / \mathrm{kg})$ and colchicine. These results suggest that MSU crystal-induced paw edema was suppressed by MPE.

\section{Effect of MPE on hind paw weight-bearing distribution}

The ratio of hind paw weight distribution between the right and left limbs was used to assess the progressive pain of gouty arthritis. The weight-bearing distribution was reduced in the MSU crystal group mice compared with that in the control group mice, although the MPEtreated group and Col-treated groups displayed a significant reversal of this MSU crystal-induced inflammatory pain in DWB measurements (Fig. 2). Consequently, the MPE treatment helped relieve the pain of MSU crystalinduced gouty arthritis.

\section{Effects of MPE on proinflammatory cytokines}

We investigated the anti-inflammatory effect of MPE on TNF- $\alpha$ and IL-1 $\beta$. The levels of these two cytokines were examined via ELISA after the injection of the MSU crystal suspension. The results showed (Fig. 3) that MSUinduced mice had significantly elevated TNF- $\alpha$ and IL$1 \beta$ levels and that treatment with MPE significantly down-regulated the production of TNF- $\alpha$ and IL-1 $\beta$. Colchicine also significantly decreased the proinflammatory cytokine levels compared with those in the MSU group. These results clearly showed that the MPE treatment inhibits the major inflammatory cytokines (TNF- $\alpha$ and IL-1 $\beta$ ), which are essential in the initiation and progression of gouty arthritis.

\section{Real-time PCR analysis}

To investigate the mechanisms underlying the antiinflammatory effects of MPE, the mRNA expression levels of inflammatory cytokines (TNF- $\alpha$ and IL-1 $)$, 


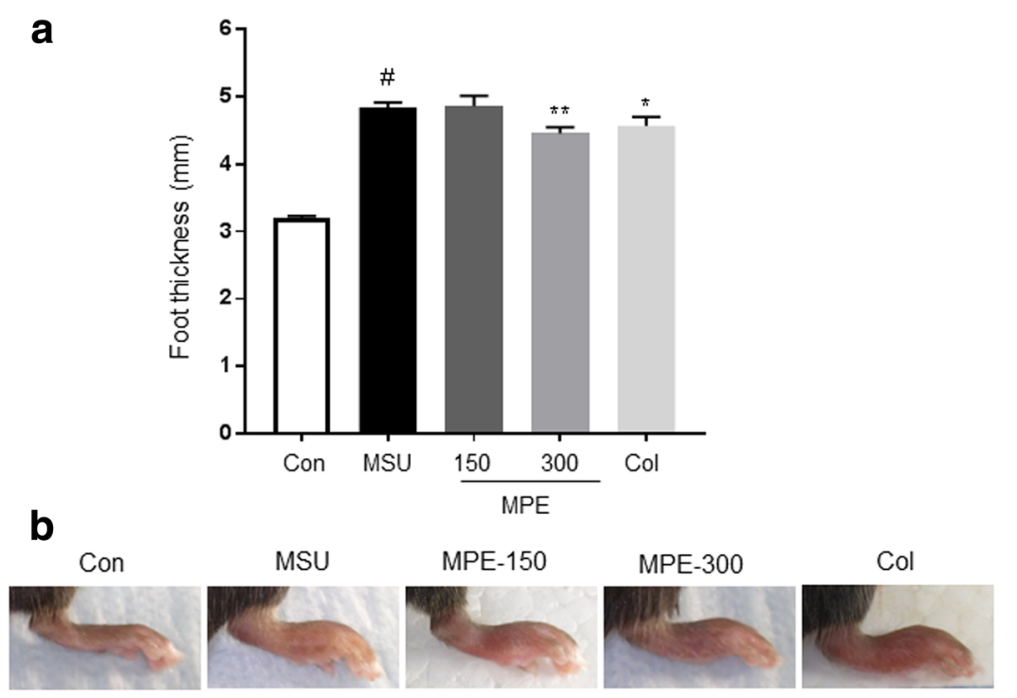

Fig. 1 Effect of MPE on paw edema in mouse with MSU crystal-induced gouty arthritis. Con, control mice; MSU, MSU crystal-induced mice; MPE-150, MSU mice treated with $150 \mathrm{mg} / \mathrm{kg}$ of MPE; MPE-300, MSU mice treated with $300 \mathrm{mg} / \mathrm{kg}$ of MPE; Col, MSU mice treated with $1 \mathrm{mg} / \mathrm{kg}$ of colchicine. a Measurement of the thickness of the each mice paw recorded at the end of the experimental period. b Representative images of the left leg from each group are shown. Data are presented as the mean $\pm \operatorname{SEM}(n=5)$. \# $p<0.0001$, vs. control group; ** $p<0.01$, vs. MSU group, ${ }^{*} p<0.05$, vs. MSU group

inflammasome components (NLRP3, ASC, caspase-1) and transcription factors $(\mathrm{NF}-\mathrm{kB})$ were determined in MSU-induced paw tissue via RT-PCR. As shown in Fig. 4, a marked increase in the mRNA expression levels of inflammatory cytokines (TNF- $\alpha$ and IL-1 $\beta$ ), NLRP3, ASC, caspase-1, and NF- $\mathrm{kB}$ was observed in the paw tissue of MSU-induced mice compared with the levels observed in the control group. Conversely, compared with the MSU group, the MSU group treated with MPE showed a dose-dependent decrease in the transcriptional level of inflammatory cytokines (TNF- $\alpha$ and IL-1 $)$ ), NLRP3, ASC, caspase-1, and NF-кB. These findings indicate that the decreased mRNA levels of NLRP3, ASC, caspase-1 and NF-кB are responsible for the reduction in cytokine production.

\section{Discussion}

Gouty arthritis is a chronic inflammatory disease characterized by swelling and severe pain of one or more synovial joints, and it is caused by disordered nucleic acid metabolism and the subsequent deposition of MSU crystals in the joints [24]. MSU crystals are proinflammatory stimuli that can initiate, amplify and sustain an intense inflammatory response. The main pathological hallmark of gout is that neutrophils accumulate in both the joint fluid and the synovial membrane after sensing the signals released from macrophages. The interaction of MSU crystal with the macrophages in the joints leads to the formation of proteins known as inflammasomes, which provide a platform for the enzymatic conversion of pro-IL-1 $\beta$ into biologically active IL-1 $\beta$. Then, the activated IL-1 $\beta$ promotes TNF- $\alpha$, which is responsible for the significant influx of neutrophils into both the joint fluid and the synovial membrane [25, 26]. Activated TNF- $\alpha$ and IL-1 $\beta$ amplify the inflammatory response and cause joint injury, and they are also activators of $N F-\kappa B[27,28]$. Thus, the activation of NF- $\mathrm{B}$ may be a key step in the pathogenesis of gouty arthritis, and the suppression of NF- $\kappa$ B likely represents an effective treatment for the treatment of gouty arthritis [29]. Therefore, the important targets for the management of inflammatory diseases, such as gouty arthritis include the reduction of swelling, pain, and inflammation by controlling the activation of inflammasomes, proinflammatory cytokines (TNF- $\alpha$ and IL-1 $\beta$ ) and NF-kB $[4,30,31]$.

In this study, we examined the anti-inflammatory effect of MPE on the production of proinflammatory cytokines (TNF-a and IL-1 $\beta$ ), which are mediators of inflammation-related gene expression in the MSU crystal-induced mice. We further evaluated the therapeutic potential of MPE for the treatment of the antiinflammatory agent by measuring the paw thickness and weight-bearing distribution in the paw tissue of MSUinduced mice.

A number of studies have demonstrated that proinflammatory cytokines including IL- $1 \beta$ and TNF- $\alpha$, and the transcription factor, NF- $\mathrm{kB}$, are important in the response to MSU injections into the joint cavity [28, 32]. The proinflammatory cytokines TNF- $\alpha$ and IL- $1 \beta$ both

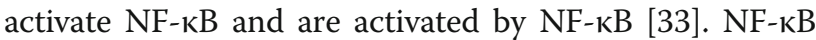




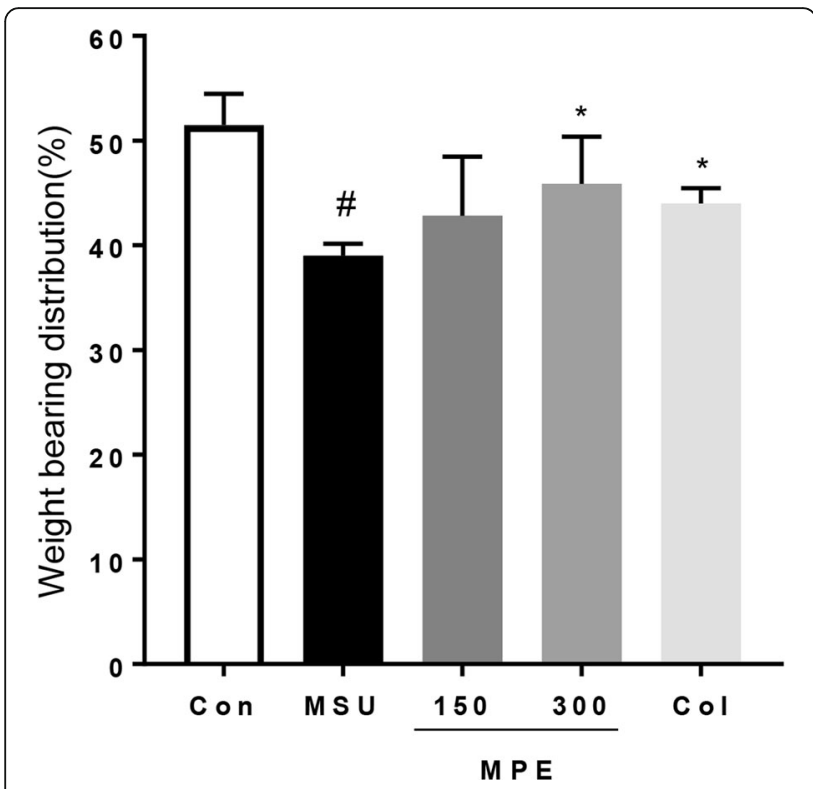

Fig. 2 Effect of MPE on changes in hind paw weight-bearing distribution in MSU-induced gouty arthritis. The weight-bearing distribution ratio was measured using a dynamic weight bearing (DWB) device, compared to that of the MSU crystal-induced group. Con, control mice; MSU, MSU crystal-induced mice; MPE, MSU mice treated with 150/300 mg/kg of MPE; Col, MSU mice treated with $1 \mathrm{mg} / \mathrm{kg}$ of colchicine. Data are presented as the mean \pm SEM $(n=5)$. \# $p<0.001$, vs. control group; ${ }^{*} p<0.05$, vs. MSU group

is a dimeric transcription factor that appears to play a major role in the regulation of inflammatory gene expression. However, under the influence of extracellular signals, such as MSU, NF- $\mathrm{kB}$ can be activated and may increase the expression of genes for proinflammatory cytokines, chemokines, enzymes, and adhesion molecules, which ultimately leads to an inflammatory response closely connected to the pathogenesis of gouty arthritis. Jaramillo et al. reported that MSU-induced NF- $\mathrm{KB}$ activation and proinflammatory cytokine secretion in the murine macrophage cell line B10R [34]. Conversely, the overexpression of TNF- $\alpha$ and IL-1 $\beta$ can directly activate the NF- $\kappa B$ pathway $[28,29]$. Han et al. showed that NF$\kappa \mathrm{B}$ are simultaneously activated in IL- 1 or TNF- $\alpha$ stimulated synoviocytes as well as the intimal synovial lining of Rheumatoid arthritis patients [35]. Our results show that MPE inhibits the production of TNF- $\alpha$ and IL- $1 \beta$ in MSU crystal-induced mice. The levels of IL-1 $\beta$ and TNF- $\alpha$ in the paw tissue were significantly increased in response to MSU, whereas this overproduction was markedly decreased by the MPE treatment, compared to the positive drug, colchicine. Additionally, the findings in the present study demonstrated that MPE prevented the MSU-induced activation of NF- $\mathrm{KB}$.

Activated NF- $\mathrm{B}$ promotes the expression of NLRP3 [36]. Recent studies have reported that epigallocatechin3-gallate can inhibit NLRP3 inflammasome activation by blocking NF- $\mathrm{B}$ activation [37]. The NLRP3 (also known as NALP3) inflammasome has been shown to form through homotypic interactions between the CARD and PYD domains of NLRP3, pyrin and the adaptor ASC (Apoptosis-associated speck-like protein containing a CARD). After MSU stimulation, the NLRP3 inflammasome is activated and induces the conversion of procaspase- 1 to active caspase- 1 , which in turn cleaves the inactive precursor cytokine pro-IL-1 $\beta$ into proinflammatory IL-1 $\beta$ [38-40]. Kingsbury et al. suggested that macrophages from mice deficient in various components of the inflammasomes including NLRP3, ASC, and caspase- 1 , could not activate IL-1 $\beta$ in response to MSU stimulation [41]. In the present study, we showed that the gene expression levels of NLRP3, ASC and caspase-1
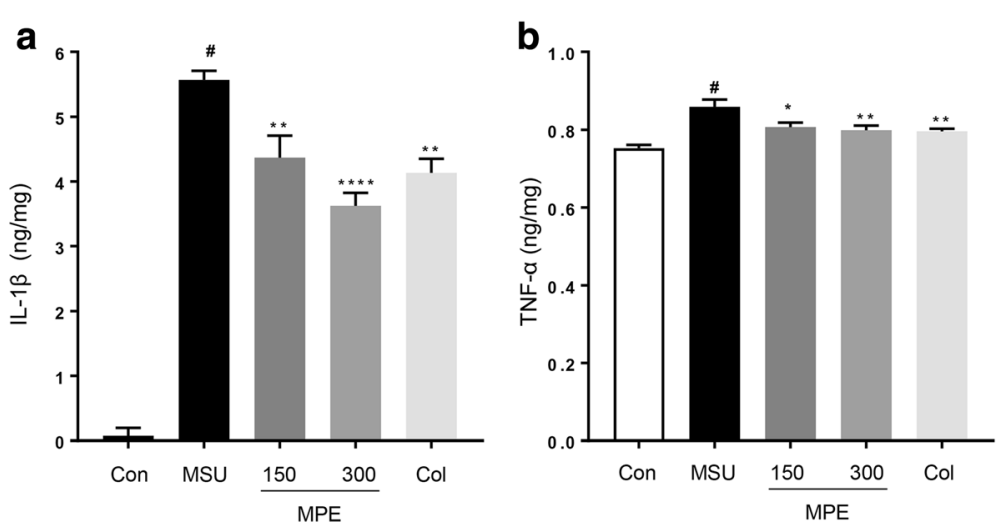

Fig. 3 Effects of MPE on expression levels of inflammatory cytokines in MSU crystal-induced gouty arthritis in mouse paw tissue. Con, control mice; MSU, MSU crystal-induced mice; MPE, MSU mice treated with 150/300 mg/kg of MPE; Col, MSU mice treated with $1 \mathrm{mg} / \mathrm{kg}$ of colchicine. a IL-1 $\beta$ and $\mathbf{b}$ TNF-a levels were measured by ELISA. Data are presented as the mean $\pm \operatorname{SEM}(n=5)$. \# $p<0.0001$ vs. control group; ${ }^{*} p<0.05$, ** $p<0.01$ and **** $p<0.0001$ vs. MSU group 


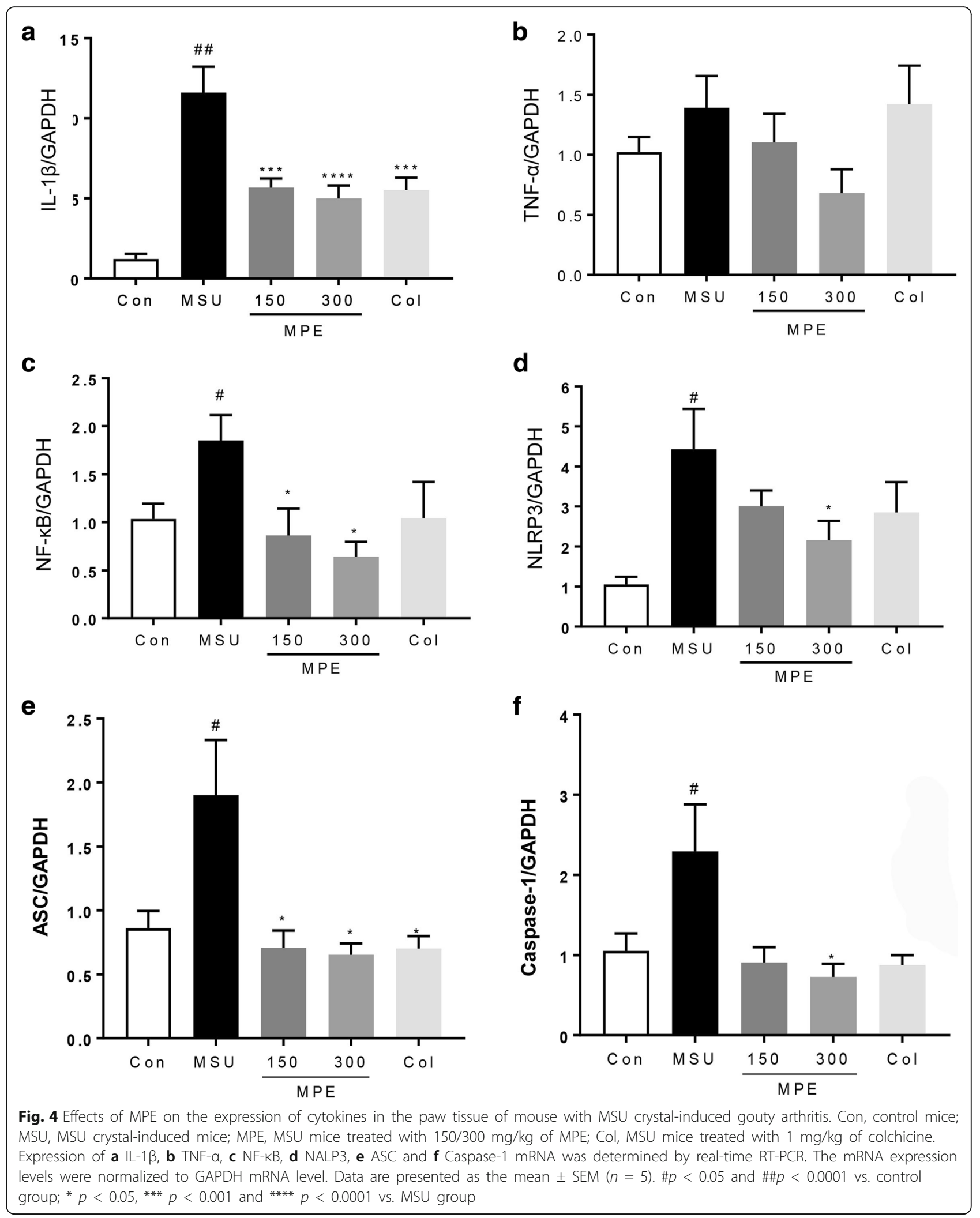


in MSU-induced mouse paw tissue were reduced after administering MPE. The decreased expressions of NALP3 by MPE further restricted the activation of caspase-1. The production of the mature forms of IL- $1 \beta$ and TNF- $\alpha$ were also decreased. We also provide evidence for a gouty arthritis-related pain-relieving effect of MPE, which significantly reduces edema and weightbearing pain in MSU-induced mice. Collectively, our results suggest that the inflammatory and gouty arthritis inhibitory effects of MPE primarily occur via the downregulation of edema, pain and inflammation through the control of inflammasomes, proinflammatory cytokines (TNF- $\alpha$ and IL-1 $\beta$ ), and NF- $\mathrm{kB}$.

\section{Conclusion}

The present study suggests for the first time that MPE suppressed MSU crystal-induced swelling and pain in mouse and exerted anti-inflammatory effect via suppressing proinflammatory cytokines (TNF- $\alpha$ and IL-1 $\beta$ ), NLRP3 inflammasome and NF-kB activation. These findings indicate the potential therapeutic effect of MPE that may inhibit gouty arthritis through blocking multiple anti-inflammatory pathways and reducing swelling and pain.

\section{Abbreviations}

MSU: Monosodium urate; MP: Mollugo pentaphylla; MPE: Extract of Mollugo pentaphylla; IL-1ß: Interleukin-1 beta; TNF-a: Tumor necrosis factor-alpha; NLRP3: NACHT, LRR and PYD domains-containing protein 3; ASC: Apoptosisassociated speck-like protein containing a CARD; NF-kB: Nuclear factor kappa-light-chain-enhancer of activated B cells

\section{Acknowledgments}

The authors would like to thank all of the colleagues who contributed to this study.

\section{Funding}

This research was supported by a grant of the Korea Institute of Oriental Medicine (K17030)

\section{Availability of data and materials}

Data are all contained within the paper.

\section{Authors' contributions}

This work was carried out in collaboration between all authors. YML and DSK designed the study and wrote the paper; ES, OSK performed research and analyzed data. All authors read and approved the final manuscript.

\section{Ethics approval and consent to participate}

All experiments that used animals were approved by the Institutional Animal Care and Use Committee of the Korea Institute of Oriental Medicine (Daejeon, Korea).

\section{Consent for publication}

Not applicable.

\section{Competing interests}

The authors declare that they have no competing interests.

\section{Publisher's Note}

Springer Nature remains neutral with regard to jurisdictional claims in published maps and institutional affiliations.
Received: 21 May 2017 Accepted: 30 August 2017

Published online: 06 September 2017

\section{References}

1. Dhanasekar C, Rasool M. Morin, a dietary bioflavonol suppresses monosodium urate crystal-induced inflammation in an animal model of acute gouty arthritis with reference to NLRP3 inflammasome, hypoxanthine phospho-ribosyl transferase, and inflammatory mediators. Eur J Pharmacol. 2016:786:116-27.

2. Perez-Ruiz F, Dalbeth N, Bardin T. A review of uric acid, crystal deposition disease, and gout. Adv Ther. 2015;32(1):31-41.

3. Margalit A, Duffin KL, Shaffer AF, Gregory SA, Isakson PC. Altered arachidonic acid metabolism in urate crystal induced inflammation. Inflammation. 1997;21(2):205-22.

4. Hainer BL, Matheson E, Wilkes RT. Diagnosis, treatment, and prevention of gout. Am Fam Physician. 2014;90(12):831-6.

5. Aran S, Malekzadeh S, Seifirad S. A double-blind randomized controlled trial appraising the symptom-modifying effects of colchicine on osteoarthritis of the knee. Clin Exp Rheumatol. 2011;29(3):513-8.

6. Neogi T. Clinical practice. Gout. N Engl J Med. 2011;364(5):443-52.

7. Abhishek A, Roddy E, Doherty M. Gout - a guide for the general and acute physicians. Clin Med (Lond). 2017:17(1):54-9.

8. Dalbeth N, Haskard DO. Mechanisms of inflammation in gout. Rheumatology. 2005:44(9):1090-6.

9. Malawista SE, Seegmiller JE. The effect of pretreatment with colchicine on the inflammatory response to microcrystalline urate: a model for gouty inflammation. Ann Intern Med. 1965;62:648-57.

10. Martinon F, Petrilli V, Mayor A, Tardivel A, Tschopp J. Gout-associated uric acid crystals activate the NALP3 inflammasome. Nature. 2006:440(7081):237-41.

11. Maroon JC, Bost JW, Maroon A. Natural anti-inflammatory agents for pain relief. Surg Neurol Int. 2010;1:80.

12. Rajasekaran M, Nair AG, Hellstrom WJ, Sikka SC. Spermicidal activity of an antifungal saponin obtained from the tropical herb Mollugo Pentaphylla. Contraception. 1993;47(4):401-12

13. Hamburger M, Dudan G, Ramachandran Naira AG, Jayaprakasama $R$ Hostettmann K. An antifungal triterpenoid from mollugo pentaphylla. Phytochemistry. 1989:28(6):1767-8.

14. Kim SS, Kim JY, Lee NH, Hyun CG. Antibacterial and anti-inflammatory effects of Jeju medicinal plants against acne-inducing bacteria. J Gen App Microbiol. 2008;54(2):101-6

15. Maiti UK, Mishra PK, Roy SK, Nandy S. Assessment of antiulcer activity of Mollugo pentaphylla Linn. in some experimental animal models. Int J Pharm Pharm Sci. 2012;4(4):488-96.

16. Lin CC, Ng LT, Yang JJ, Hsu YF. Anti-inflammatory and hepatoprotective activity of peh-hue-juwa-chi-cao in male rats. Am J Chin Med. 2002:30(2-3):225-34

17. Sahu SK, Das D, Tripathy NK, Sundeepkumar HK, Banerjee M. Antiinflammatory, analgesic and antipyretic effects of Mollugo Pentaphylla L. RASAYAN J Chem. 2011;4(3):533-8.

18. Moilanen LJ, Hamalainen M, Lehtimaki L, Nieminen RM, Moilanen E. Urate crystal induced inflammation and joint pain are reduced in transient receptor potential ankyrin 1 deficient mice-potential role for transient receptor potential ankyrin 1 in gout. PLoS One. 2015;10(2):e0117770.

19. Sung YY, Kim DS, Kim HK. Viola mandshurica ethanolic extract prevents high-fat-diet-induced obesity in mice by activating AMP-activated protein kinase. Environ Toxicol Pharmacol. 2014;38(1):41-50.

20. Rasool M, Varalakshmi P. Suppressive effect of Withania somnifera root powder on experimental gouty arthritis: an in vivo and in vitro study. Chem Biol Interact. 2006:164(3):174-80.

21. Otsuki T, Nakahama $H$, Niizuma $H$, Suzuki J. Evaluation of the analgesic effects of capsaicin using a new rat model for tonic pain. Brain Res. 1986;365(2):235-40

22. Laux-Biehlmann A, Boyken J, Dahllof H, Schmidt N, Zollner TM, Nagel J. Dynamic weight bearing as a non-reflexive method for the measurement of abdominal pain in mice. Eur J Pain. 2016;20(5):742-52.

23. Lolignier S, Amsalem M, Maingret F, Padilla F, Gabriac M, Chapuy E, Eschalier A, Delmas P, Busserolles J. Nav1.9 channel contributes to mechanical and heat pain hypersensitivity induced by subacute and chronic inflammation. PLoS One. 2011;6(8):e23083.

24. Agudelo CA, Wise CM. Gout: diagnosis, pathogenesis, and clinical manifestations. Curr Opin Rheumatol. 2001;13(3):234-9. 
25. Nuki G. Colchicine: its mechanism of action and efficacy in crystal-induced inflammation. Curr Rheumatol Rep. 2008;10(3):218-27.

26. Scanu A, Oliviero F, Ramonda R, Frallonardo P, Dayer JM, Punzi L. Cytokine levels in human synovial fluid during the different stages of acute gout: role of transforming growth factor beta1 in the resolution phase. Ann Rheum Dis. 2012;71(4):621-4.

27. Baeuerle PA, Henkel T. Function and activation of NF-kappa B in the immune system. Annu Rev Immunol. 1994;12:141-79.

28. Ma Y, Zhou LL, Yan HY, Liu M. Effects of extracts from Paederia scandens (LOUR.) MERRILL (Rubiaceae) on MSU crystal-induced rats gouty arthritis. Am J Chin Med. 2009;37(4):669-83.

29. Grilli M, Chiu JJ, Lenardo MJ. NF-kappa B and Rel: participants in a multiform transcriptional regulatory system. Int Rev Cytol. 1993;143:1-62.

30. Doss HM, Dey C, Sudandiradoss C, Rasool MK. Targeting inflammatory mediators with ferulic acid, a dietary polyphenol, for the suppression of monosodium urate crystal-induced inflammation in rats. Life Sci. 2016;148:201-10.

31. Richette P, Bardin T. Gout. Lancet. 2010;375(9711):318-28.

32. Punzi L, Scanu A, Ramonda R, Oliviero F. Gout as autoinflammatory disease: new mechanisms for more appropriated treatment targets. Autoimmun Rev. 2012;12(1):66-71.

33. Barnes PJ, Karin M. Nuclear factor-kappaB: a pivotal transcription factor in chronic inflammatory diseases. N Engl J Med. 1997;336(15):1066-71.

34. Jaramillo M, Godbout M, Naccache PH, Olivier M. Signaling events involved in macrophage chemokine expression in response to monosodium urate crystals. J Biol Chem. 2004:279(50):52797-805.

35. Han Z, Boyle DL, Manning AM, Firestein GS. AP-1 and NF-kappaB regulation in rheumatoid arthritis and murine collagen-induced arthritis. Autoimmunity. 1998;28(4):197-208.

36. Bauernfeind FG, Horvath G, Stutz A, Alnemri ES, MacDonald K, Speert D, Fernandes-Alnemri T, Wu J, Monks BG, Fitzgerald KA, et al. Cutting edge: NF-kappaB activating pattern recognition and cytokine receptors license NLRP3 inflammasome activation by regulating NLRP3 expression. J Immunol. 2009;183(2):787-91.

37. Tsai PY, Ka SM, Chang JM, Chen HC, Shui HA, Li CY, Hua KF, Chang WL, Huang JJ, Yang SS, et al. Epigallocatechin-3-gallate prevents lupus nephritis development in mice via enhancing the Nrf2 antioxidant pathway and inhibiting NLRP3 inflammasome activation. Free Radic Biol Med. 2011;51(3):744-54

38. Lo YH, Huang YW, Wu YH, Tsai CS, Lin YC, Mo ST, Kuo WC, Chuang YT, Jiang ST, Shih HM, et al. Selective inhibition of the NLRP3 inflammasome by targeting to promyelocytic leukemia protein in mouse and human Blood. 2013;121(16):3185-94.

39. Bauernfeind F, Ablasser A, Bartok E, Kim S, Schmid-Burgk J, Cavlar T, Hornung V. Inflammasomes: current understanding and open questions. Cell Mol Life Sci. 2011;68(5):765-83.

40. van de Veerdonk FL, Netea MG, Dinarello CA, Joosten LA. Inflammasome activation and IL-1 beta and IL-18 processing during infection. Trends Immunol. 2011;32(3):110-6.

41. Kingsbury SR, Conaghan PG, McDermott MF. The role of the NLRP3 inflammasome in gout. J Inflamm Res. 2011;4:39-49.

\section{Submit your next manuscript to BioMed Central and we will help you at every step:}

- We accept pre-submission inquiries

- Our selector tool helps you to find the most relevant journal

- We provide round the clock customer support

- Convenient online submission

- Thorough peer review

- Inclusion in PubMed and all major indexing services

- Maximum visibility for your research

Submit your manuscript at www.biomedcentral.com/submit

) Biomed Central 